\title{
Method for a cloud based remaining-service-life-prediction for vehicle-gearboxes based on big-data-analysis and machine learning
}

\author{
Daniel Vietze ${ }^{1}$ (D) $\cdot$ Michael Hein ${ }^{1}$ (D) Karsten Stahl $^{1}$ (D) \\ Received: 31 March 2020 / Accepted: 5 September 2020 / Published online: 28 September 2020 \\ (c) The Author(s) 2020
}

\begin{abstract}
Most vehicle-gearboxes operating today are designed for a limited service-life. On the one hand, this creates significant potential for decreasing cost and mass as well as reduction of the carbon-footprint. On the other hand, this causes a rising risk of failure with increasing operating time of the machine. Especially if a failure can result in a high economic loss, this fact creates a conflict of goals. On the one hand, the machine should only be maintained or replaced when necessary and, on the other hand, the probability of a failure increases with longer operating times. Therefore, a method is desirable, making it possible to predict the remaining service-life and state of health with as little effort as possible.

Centerpiece of gearboxes are the gears. A failure of these components usually causes the whole gearbox to fail. The fatigue life analysis deals with the dimensioning of gears according to the expected loads and the required service-life. Unfortunately, there is very little possibility to validate the technical design during operation, today. Hence, the goal of this paper is to present a method, enabling the prediction of the remaining-service-life and state-of-health of gears during operation. Within this method big-data and machine-learning approaches are used. The method is designed in a way, enabling an easy transfer to other machine elements and kinds of machinery.
\end{abstract}

\section{Methode für eine Cloud-basierte Restlebensdauerprognose für Fahrzeuggetriebe basierend auf Big-Data-Analysen und Machine Learning}

\section{Zusammenfassung}

Die meisten heutzutage eingesetzten Fahrzeuggetriebe sind für eine endliche Betriebsdauer ausgelegt. Dies eröffnet erhebliches Potential für Gewichts- und Kostenreduktion sowie Verbesserung der $\mathrm{CO}_{2}$-Bilanz. Jedoch ist der langfristige Betrieb mit zunehmender Wahrscheinlichkeit eines Schadens verbunden. Insbesondere, wenn der Ausfall einen hohen wirtschaftlichen Schaden verursacht, entsteht hierdurch ein Zielkonflikt aus steigendem Ausfallrisiko und frühzeitiger Außerbetriebsetzung bzw. überhöhten Instandhaltungskosten. Um diesen Konflikt aufzulösen, ist eine Methodik wünschenswert, die es ermöglicht, mit möglichst geringem Aufwand die verbleibende Lebensdauer und den aktuellen Gesundheitszustand eines Fahrzeuggetriebes laufend abzuschätzen.

Die Kernkomponenten von Fahrzeuggetrieben sind die Zahnräder, deren Schaden meist zum Ausfall des gesamten Getriebes führt. Die Betriebsfestigkeitsrechnung befasst sich seit Langem mit der Dimensionierung von Zahnrädern entsprechend der zu erwartenden Belastungen und der geforderten Lebensdauer. Während des Betriebs ist es aber bisher kaum möglich, die hierzu erforderlichen Annahmen zu überprüfen. Im Rahmen dieser Veröffentlichung wird eine Methode präsentiert, die es ermöglicht, die Restlebensdauer und den Gesundheitszustand von Verzahnungen laufend während des Betriebs zu prognostizieren. Hierbei werden Big-Data-Ansätze und Methoden der künstlichen Intelligenz verwendet. Das grundlegende Konzept ist hierbei so ausgestaltet, dass eine Übertragung der Methode auf andere Maschinenelemente und Maschinenarten gut möglich ist.

Daniel Vietze

vietze@fzg.mw.tum.de

Michael Hein

hein@fzg.mw.tum.de
Karsten Stahl

stahl@fzg.mw.tum.de

1 FZG-Gear Research Centre, Technical University of Munich (TUM), Boltzmannstraße 15, 85748 Garching bei Munich, Germany 


\section{Motivation}

Transmissions are a key component of vehicle drive trains. Cars, powered both, by electric and internal combustion engine, trucks, trains and constructional and agricultural machinery would not work the usual way without gearboxes in their drive trains. Over the last decades these components have become more and more sophisticated and capable of transferring more and more power, while at the same time becoming even lighter and more compact. At the heart of nearly every gearbox are the gears, realizing the transmission of the engine torque and reducing or increasing the rotational speed of the engine.

Research institutions and development departments all over the world are working on increasing the load carrying capacity and the reliability of high performance gears. Nevertheless, failures occur and can lead to a total loss of drive. With increasing lifetime and millage this becomes more and more likely, creating a conflict of goals especially for owners of commercially used vehicles. On the one hand the vehicle should only be maintained or replaced when necessary and, on the other hand the increasing probability of a failure, causing expensive downtime, creates a serious economic risk. Additionally, the ecological footprint of a vehicle is increased unnecessarily if maintenance or replacement takes place earlier than necessary. Therefore, a method is desirable making it possible to constantly predict the remaining service-life of the gearbox considering the actual operating conditions without taking the gearbox apart or installing a lot of expensive equipment.

Usually gears used in vehicle transmissions are dimensioned in a way that they only can withstand the operational load for a certain amount of load cycles. This approach enables a reduction of weight, size and cost of the transmission. To safely reach the calculated end of service-life the occurring loads have to be within the predicted load spectrum and the strength of the gears has to be within the allowed tolerance margin. Especially unconsidered overloads and their effects are a large source of uncertainty.

Over the last couple of years more and more sensors have been included in machinery of every kind. Utilizing the data created by these sensors is a major part of the megatrend Industry 4.0. Because of the increasing availability of modern mobile networks, like $5 \mathrm{G}$, it is possible to create a data connection nearly everywhere. Today predictive maintenance is using this data and connectivity to predict whether a machine needs to be maintained. Sometimes these methods also make predictions about the remaining service-life, but the high potential of the knowledge and methods of fatigue life analysis is not utilized.

Modern vehicles, especially electric cars, are able to provide a lot of data regarding their drive train. For example, an electric motor is able to deliver a signal of the out- put torque at any given moment. Goal of this paper is to present a method, which uses such data to estimate the state of health and predict the remaining service-life of a vehicle transmission, while utilizing the knowledge of fatigue life analysis and including the potential of machine-learning and big data. This paper presents the whole concept in an easy understandable and accessible way and does not specify the method and its calculation in every detail. At the beginning, the required knowledge about fatigue life analysis is presented in a compact summary. Afterwards the method is presented in four steps, where every of these steps expands the concept up to the full remaining-servicelife-prediction.

\section{State of the art}

\subsection{Fatigue life calculation of gears}

Gears can fail due to numerous kinds of damage. Not all of these damages can be analyzed with the methods of the fatigue life analysis. Some damages like scuffing can occur after just one load cycle under critical conditions. Other damages like pitting and tooth root breakage are typical fatigue failure mechanism and are usually caused by a high number of load cycles and can be analyzed using the methods of the fatigue life analysis [11].

Usually gears in vehicle transmissions can only withstand the load occurring in operation for a limited amount of load cycles. Especially the highest loads cannot be tolerated many times. To describe this load carrying capacity the "Woehler" curve/S/N-curve (also known as "Woehler" damage line) is often used. A typical "Woehler" curve/S/Ncurve is shown in Fig. 1. This graph shows how many load cycles of one particular load can be tolerated at a certain probability of failure. The "Woehler" curve/S/N-curve can be divided up into three characteristic areas [10]:

- Loads higher than the static strength cannot be withstand for even one load cycle. If loads above the static strength occur the gear fails immediately. (red zone in Fig. 1-static strength)

- Loads lower than the endurance limit can be tolerated for more load cycles then considered relevant for the use case (usually between $10^{6}-10^{8}$ load cycles for gears). (green zone in Fig. 1-area of infinite life)

- Loads between these two zones can be tolerated for a limited amount of load cycles. The Woehler line has a negative slope in this area, because the amount of permissible load cycles increases with decreasing load. (yellow zone in Fig. 1-area of limited life)

To dimension gears according to the rules of fatigue life analysis a load spectrum is required additionally to the 


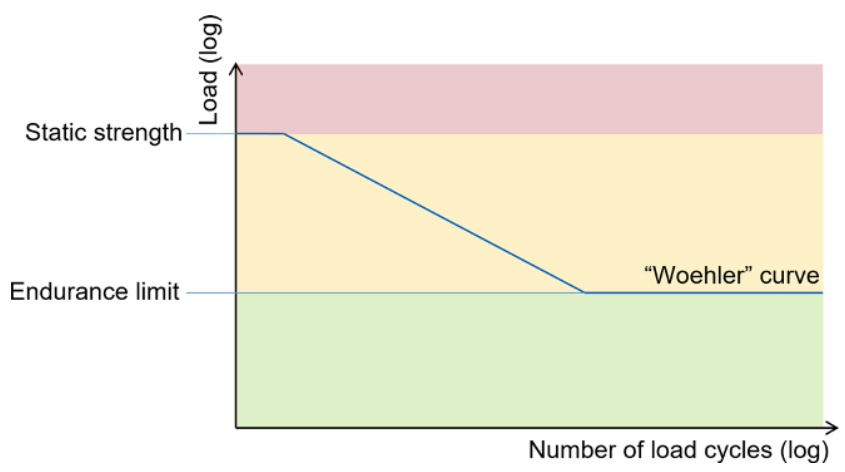

Fig. 1 Typical "Woehler" curve/S/N-curve

"Woehler" curve/S/N-curve. Load spectra deliver the information about the loads occurring during operation. These usually divide up the whole range of occurring loads into a certain amount of discrete levels. The load spectrum delivers the information how often a load of a certain level will occur during the operation. An example for such a load spectrum is shown in Fig. 2.

Damage accumulation hypotheses are used to connect the load carrying capacity and the load spectrum [10]. These predict how likely a damage is, when a certain load spectrum is applied to a gear. Linear damage accumulation hypotheses are most common for the herein considered use case. These are based on the assumption, that every load cycle of one load level is causing the same amount of damage regardless of when it occurs. The linear hypotheses calculate a partial damage sum for every load level and add all these partial damage sums up to the damage sum. If this damage sum exceeds a threshold a failure is likely to occur for the considered probability of failure.

The simplest and most widely used linear damage accumulation hypotheses is the "Miner-rule" [15]. This hypotheses exist in the original, elementary and modified form according to Miner-Haibach [10,15]. The three variants differ by the consideration of loads below the endurance limit.

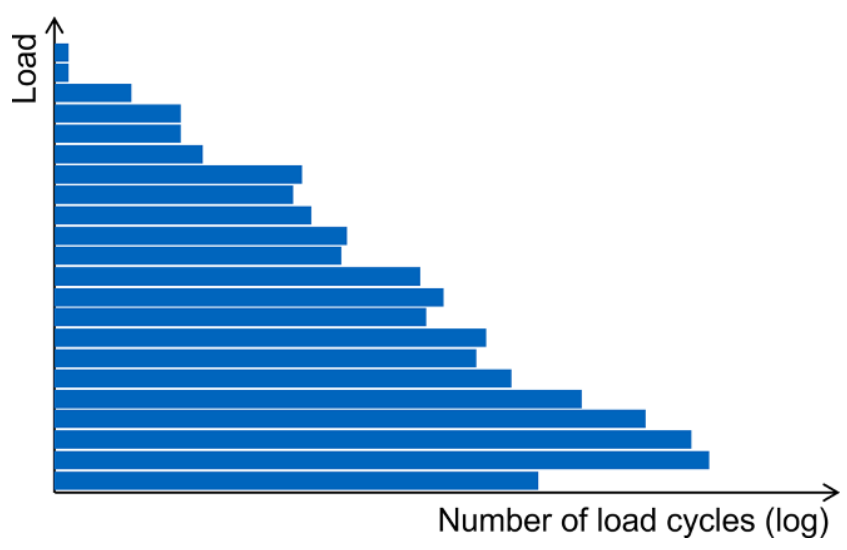

Fig. 2 Example for a load spectrum

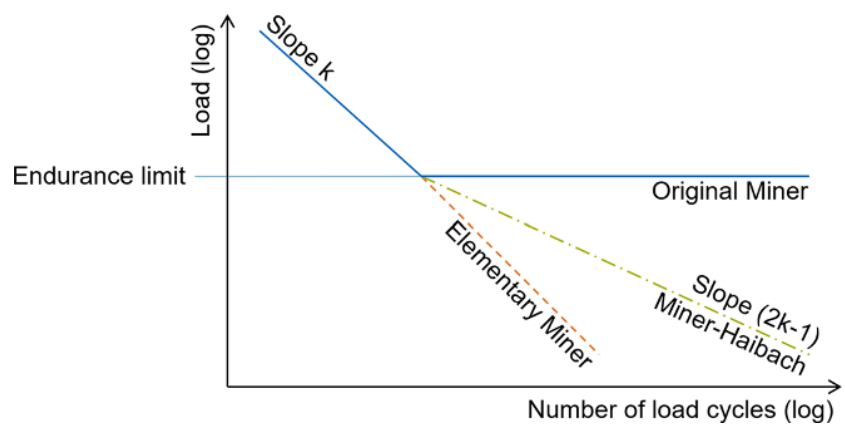

Fig. 3 Number of tolerable load cycles assumend by three different damage accumulation hypotheses

It is known from experimental investigations [19] that loads in the area of limited life (loads between the endurance limit and the static strength) can lead to a significant reduction of the resulting endurance limit if tests are continued at lower loads. If the decisive load spectrum contains a significant number of loads above the endurance limit, loads lower than original endurance limit can cause damage to the gears and therefore should be considered in the calculation of the damage-sum as well as the servicelife-prediction. The original form of the Miner-rule does not take loads lower than the original endurance limit into account. The other two forms apply a different weighing for loads lower than the endurance limit. The elementary form by Miner considers these loads with a higher impact on the total damage than the modified form by MinerHaibach. Fig. 3 shows how the three hypotheses assume the maximal endurable number of load cycles is developing over the load. Within the original form of the Minerrule the load-cycle-limit follows the "Woehler" curve/S/Ncurve and therefor assumes an unlimited number of tolerable cycles for loads lower than the endurance limit. Both other forms use different limits for loads lower than the endurance limit.

A weak spot of linear damage accumulation hypotheses is the fact, that they do not take the chronology of the loads into account. Experimental investigation have shown that the sequence of loads can have influence on the life time. Hein [11] has shown that a pitting damage will occur at a significantly higher damage sum if the loads where applied with a more frequent mix of high and low loads. Such effects cannot be taken into account by linear damage accumulation hypotheses and therefor the accuracy of the service-life-prediction based on those is limited.

There are different approaches in the fatigue life analysis which address these issues, for example the methods of the fracture mechanics [2] or nonlinear damage accumulation hypotheses [18]. But these methods are linked to a significantly higher effort and often need a lot of very precise 
input data. Therefor these methods are not common to be used for the fatigue life analysis of gears.

\subsection{Condition monitoring and predictive maintenance}

The preceding section shortly summarized the basics of the fatigue life analysis. Due to the increasing spread of sensors in machinery more and more operation data is recorded and approaches to monitor the condition of machine elements were developed. The analysis of this recorded data can supply valuable information for the further operation. Predictive maintenance utilizes this data to predict if a machine needs to be maintained in the nearby future. The goal of this approach is to reduce downtime and decrease operating costs. Main emphasis of this methods is to analysis the present data delivered by the sensors. At the moment the evaluation of vibrations is widely used in this field [1, $7,8]$. But it is also possible to use different data, like the transmission error, to evaluate the status of a gearbox [9]. These methods can be used without experimental investigations upfront, if a sufficient amount of recorded data is available. Commercial software tools offer the opportunity to analyze such a data-base with machine-learning methods and to use the results to constantly monitor machinery and predict whether it is healthy or requires maintenance or replacement.

Vibration based monitoring of machinery is only able to recognize damage if the damage already is causing a change of the vibration. Especially for the monitoring of fatigue damages this can be a challenge, because the damage can grow without significant impact on the vibrations. To predict the remaining service-life of a gearbox with special regard to fatigue failure modes, it is not sufficient to analyze the current status. The history has also to be taken into account. At the moment only very few publications address a constant prediction of the remaining service-life of gearboxes.

Publications by Foulard et al. [3-6] presented a method using a signal of the input torque of a vehicle gearbox to constantly estimate its state of damage. The remaining service-life is also predicted with this approach. Linear damage accumulation hypotheses are utilized for this prediction. Therefor it is not possible to incorporate the chronology of the loads. If a very high load or overload is occurring its possible effects on the resulting endurance limit of the gears cannot be taken into account. The whole presented approach only focuses on one gearbox and does not analyze a whole fleet of identical gearboxes, like within a fleet of electric cars.

The following chapters will present a method for a remaining-service-life-prediction utilizing as much potential of big-data, machine-learning and fatigue life analysis as possible, while remaining as simple and cost efficient as possible. The whole concept is meant to be a cloud-based service. All calculations and analysis shall not take place on the onboard systems of the vehicles. The vehicles only send recorded sensor-data to a server farm and receive the results of the calculation.

\section{3 "Woehler" curve/S/N-curve, remaining life line and state of health}

In an electric car the wheels are driven by an electric motor. The output torque of this motor is usually transferred through a gearbox before being delivered to the wheels. The gearbox normally reduces the rotational speed and increases the torque. This approach enables the use of a smaller motor operating at a higher rotational speed. Usually the gearbox uses spur gears to convert the torque and rotational speed. This type of gears is known for its high efficiency, little space requirement and economic production cost [16].

As presented in Sect. 3 these gears are usually designed for a limited service-life. The "Woehler" curve/S/N-curve is often used to describe this limited load carrying capacity. With every load cycle the remaining load carrying capacity is reduced. This happens during the operation up to the moment when the gear fails. To visualize this change of load carrying capacity the remaining life line is introduced in this paper. This line starts out identical to the "Woehler" curve/S/N-curve and describes the remaining load carrying capacity of a certain pair of gears during their lifetime. Fig. 4 shows a "Woehler" curve/S/N-curve and a remaining life line after a certain operation-time. Because of the already occurred loads the load carrying capacity described by the remaining life line is lower than the one described by the "Woehler" curve/S/N-curve.

The remaining load carrying capacity of the gears will reduce during the operation until the moment when one of the gears fails. The failure occurs when a higher load is applied than the highest load that can be tolerated at the given moment. The gap between the "Woehler" curve/S/Ncurve and the remaining life line can be interpreted as the

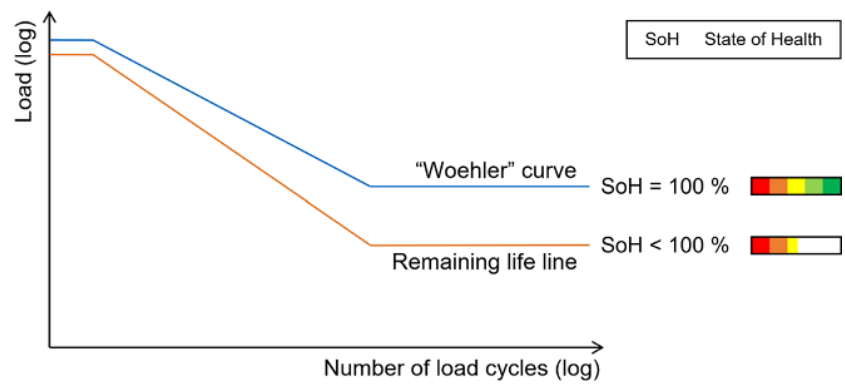

Fig. 4 "Woehler" curve/S/N-curve and remaining life line 
state of health of the gears. For a new gear both curves are identical and the state of health is at $100 \%$. During the operation this gap will increase and the state of health will decrease.

The remaining life line can be calculated using the "Woehler" curve/S/N-curve as a starting point. Furthermore a signal is needed, which is characteristic for the load of the gears. A possible signal is the input torque of the gearbox. In an electric car this torque usually is equal to the output torque of the electric motor, because no clutches or torque-converters are used between the two. There are two main-options to determine the torque driving the gearbox. The simplest and most cost-effective approach is to use the data of the power electronic to calculate the torque of the motor. Based on the electric current passing through the motor a signal of the torque can be created. This approach has a limited accuracy and may not be able to detect every peak of the torque. Therefor the state of health prediction based on this signal will have a limited reliability. But in the best-case scenario this approach will not generate any extra cost, because the only requirements are data storage space or an "always-online-ability" and computing power.

The second approach is to use a dedicated sensor to measure the input torque of the gearbox. Such a sensor can generate a very accurate signal of the input torque [6]. Of course, this approach requires space and generates cost. Therefor it is only appropriate if the value of the knowledge of the state of health prevails the arising cost. For example, in a vehicle used for exceptional load transportation this knowledge is very valuable and most certainly worth the extra cost, because the gearbox of such a vehicle is usually expensive and a failure would result in critical downtime or even threat to the cargo or humans.

Through continuous analysis of the signal with a damage accumulation hypothesis the remaining load carrying capacity can be calculated and expressed as the remaining life line. This calculation can be done using known damage accumulation hypotheses or using machine learning tools. To train methods like deep learning training data is required. In the best case this data shall exist of the whole load-timerecord and the moment of failure. It is possible to generate this data with experimental investigations or by using the data recorded by a fleet of vehicles. This recorded data can be spilt up into the one of gearboxes which already failed and the one of gearboxes which are still operating. The data of the failed ones can be used straight forward to determine the load carrying capacity of the gears. Additionally, the data of the gearboxes still operation can be used to increase the accuracy of this prediction and determine the scattering of the load carrying capacity more accurate. Here for the data has to considered combined with the knowledge that the gear can only fail due to more damage than already

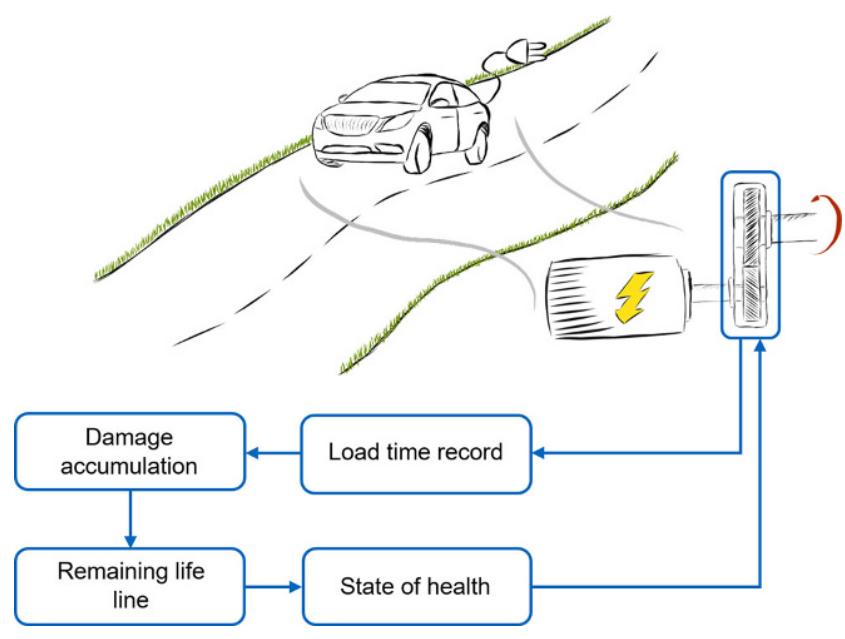

Fig. 5 Dataflow for the state of health estimation

occurred and therefor at the moment represents a minimal load carrying capacity.

The high potential of the machine learning approach is the ability of deep learning to discover connections between the failure and the occurring loads, which would not have been considered by classic damage accumulation hypotheses.

A very promising approach is the combination of both. If there is very little data yet to train the deep learning algorithms, it will be useful to apply the knowledge of the fatigue life analysis to calculate the damage and predict the state of health. This will usually be the case at the beginning of the service life of certain type of gearbox. With increasing millage and ongoing service life more and more data will have be recorded for this type of gearbox. Therefor the machine learning approach will be able to increase in accuracy and adapted to this type of gearbox and may deliver more accurate predictions compared to the known methods.

The order of the single steps of such a prediction of the state-of-health and the according data-flow of the presented method is shown in Fig. 5. As example an electric car is chosen. This example will be expanded over the course of the following chapters up to the whole concept of the remaining-service-life-prediction.

\section{Adaptive "Woehler" curve/S/N-curve utilizing big-data-analysis and machine learning}

"Woehler" curves/S/N-curves are usually the basis of service-life calculations in the field of fatigue life analysis and are created through experimental investigations. Usually experimental investigations for the load carrying capacity (Woehler-Tests) are carried out during the design process 
of the gearbox for the used materials. The "Woehler" curve/S/N-curve used for the service-life-calculation is based on those investigations [13]. During the manufacturing process of the gears a lot of parameters will be within a certain margin of tolerance and will change over the different produced batches, for example the hardness of the surface. This can have effects on the load carrying capacity [12]. These effects will not be considered within the "Woehler" curve/S/N-curve and therefore not within the service-life-calculation. Another uncertainty are the operational conditions the gears will be used with. For example the temperature, humidity or local characteristics, like sea salt, may have an influence on the service-life of the gears.

To account for all these factors within the design phase of the gears is nearly impossible and would require a vast amount of experimental investigations. Hence, a different approach to consider these factors within a service-life-prediction has to be utilized.

A lot of gears are not custom-made and therefor used in a big amount of machinery. For example the gears used in cars are a mass product and operating all over the world. All these machines can be utilized as test racks for the gears, if data about the occurring loads can be recorded and it is possible to transfer this data to a central database. The optimum solution would be a cloud computing based approach. Today nearly every modern car has the ability to connect to a mobile data network and to receive or send data.

The load-record of the gears can be used to constantly calculate the expected damage. The results of this can be used to validate the "Woehler" curve/S/N-curve, as long as a statistically relevant number of gears is monitored.

The damage can be calculated using a damage accumulation hypothesis or a machine learning based approach (see Sect. 4). In order to calculate the damage, the load record sent by the vehicle has to be classified in load levels and divided into load cycles. This data can then be used to calculate the damage sum at any given moment. Additionally to this damage sum the actual status of the gear has to be known. The simplest case is to separate the gears into those already failed and those still operating. With this information it is possible to validate the "Woehler" curve/S/N-curve or the permissible damage sum and eventually make adjustments to it. The "Woehler" curve/S/N-curve describes the load carrying capacity of the gears. A damage accumulation hypothesis predicts the failure of the gears after a certain amount of damage occurred. This prediction is based on the "Woehler" curve/S/N-curve and the occurring loads. The failures will be distributed over a certain spread of the damage sum. If the distribution of failures occurring in reality dose not match with the distribution predicted by the damage accumulation hypothesis, the load carry- ing capacity is not represented correctly by the "Woehler" curve/S/N-curve. For example, if failures are occurring at damage sums at which the prediction is not expecting any failures yet, the load carrying capacity is overestimated. This system also works if the statistics of the prediction is already expecting failures but the gears are still operating without issue, then the load carrying capacity is underestimated. In a final step the "Woehler" curve/S/N-curve can be adjusted to fit better to the actual load carrying capacity of the gears.

Within this process machine learning could open up a lot of potential. The distribution of the damages over the damage sum is normally described by mathematical probability distributions like the Weibull distribution [14]. Machine Learning could enable the analysis of this distribution without using mathematical probability distributions. The algorithms could learn the optimal distribution by simply analyzing the data. Therefor it could be possible to find an even better fitting description of the distribution and use this to make the service life prediction more accurate for future product generations.

This system can be used in a way evaluating the load carrying capacity of all monitored gears together. A more powerful approach is to use big-data-methods and machine learning to cluster the gears into groups and monitor these groups separately.

Big-data-tools based on machine learning are able to analyze a lot of data and find similarities, which would have remained hidden to the human eye. Usually unsupervised machine learning is used for such tasks. Unsupervised machine learning is generally used, if the data used to train the methods is unlabeled. Unlabeled data refers to the fact that the solution to the problem is unknown [17]. In the presented concept unknown solution refers to the fact, that the criteria to cluster the data by is not known to the user, but instead shall be found by the algorithms. Therefor the algorithms are trained without knowing the result in advance.

For example, it can be useful to separate the gears according to the height gradient of the roads they are operating on, according to the climate or by their production batches. These groups can be monitored separately and the "Woehler" curve/S/N-curve can be adjusted to represent the load carrying capacity as accurate as possible. In this presented manner an adaptive "Woehler" curve/S/N-curve can be created, which enables to predict the service-life of gears more accurate. To evaluate the trained model for clustering the data the results have to be checked by the user. Especially, the comparison of the quality of the results with a calculation without the clustering is important. This enables the user to decide whether the clustering approach provides an increasing accuracy or if the analysis of the whole data without clustering provides a better or similar good prognosis. 
Fig. 6 Dataflow expanded by the adaptive "Woehler" curve/S/N-curve

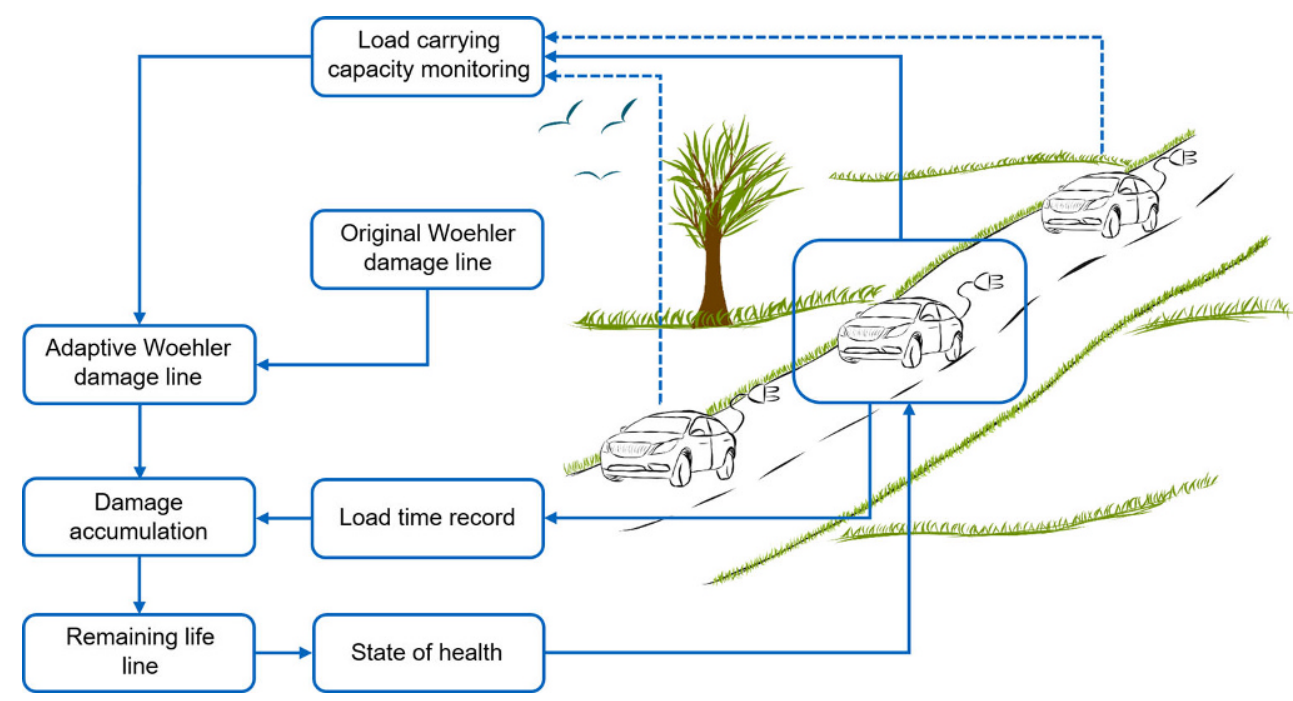

Additionally, it is possible to combine the machine learning based clustering of the operating units with clustering done by the user. This combination is often referred to as scientific machine learning.

The data-flow for this adaptive "Woehler" curve $/ \mathrm{S} / \mathrm{N}$ curve is shown in Fig. 6. Within this figure the example of the electric car used in Sect. 4 is taken up again and expanded by the adaptive "Woehler" curve/S/N-curve.

\section{Using big-data-analysis to increase the validity of load spectra}

The preceding chapters dealt with the load carrying capacity and a way to increase the validity of the "Woehler" curve/S/N-curve, the used damage accumulation hypothesis and the permissible damage sum. Additionally to the load carrying capacity the operational loads have to be known or predicted for a dimensioning according to the fatigue life analysis and are required for a remaining-service-lifeprediction.

The loads are usually characterized via load spectra. To generate load spectra accurately representing the actual operation of the gears can be challenging. Using records of the actual loads occurring in operation is common practice. Such a load spectrum can be used for the dimensioning of the gears.

How a customer is going to use a vehicle cannot be predicted with high reliability. Therefor it is not optimal to use the original load spectrum to predict the remaining servicelife of a gear in operation. The recorded load-data used in Sect. 5 to validate the "Woehler" curve/S/N-curve can also be utilized to increase the accuracy of the load spectrum applied for the service-life prediction of the gears. Big-datamethods can be used in a similar manner to Sect. 5. Clus- tering the gears into groups with similar load characteristics can be useful to predict the service-life more accurate. This clustering can also be used for future developments. For example it is conceivable to adjust the load carrying capacity of a gearbox according to the costumer. This approach can be useful for commercial customers and save money and reduce expensive downtime. The dataflow for the clustering and the individual load spectrum of each cluster is shown in Fig. 7.

The presented method can be used to create an adaptive load spectrum or many load spectra depending on the use case. If only one adaptive load spectrum for all vehicles is required, the clustering will not be applied due to the fact that all vehicles are in the same cluster. In some cases, it can be considered optimal to adapt the original load spectrum for every gearbox separately and in other case it may be optimal to separate the gearboxes into groups with one common load spectrum according to their operational characteristics. This can be controlled by the number of clusters used.

Fig. 8 shows the data flow for the adaptive load spectrum integrated in the data flow of the preceding chapter. The spectrum uses the original load spectrum as a starting point and adjusts accordantly to the occurring loads. The adaptive load spectrum will be put to use in the following chapter, when the whole concept is shown.

\section{Method for an online remaining-service- life-prediction}

The three preceding chapters presented elements of the concept for a remaining-service-life-prediction. This chapter unites all these steps to the whole concept. The prediction of the remaining-service-life uses a damage accumulation 
Fig. 7 Dataflow for the clustering and analysis of the adaptive load spectrum

Fig. 8 Dataflow expended by the adaptive load spectrum
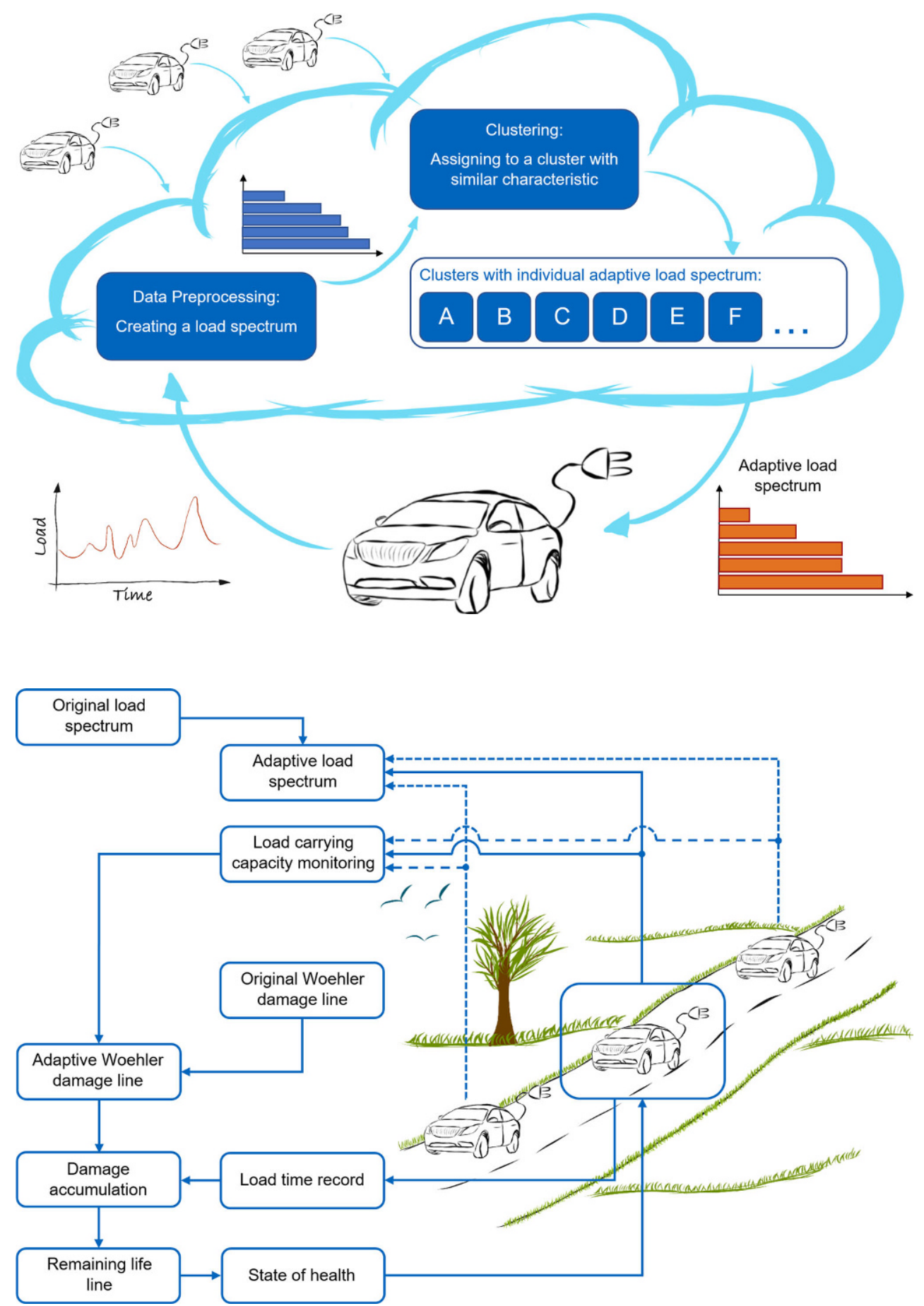

to calculate how much longer the gear will withstand the loads occurring in operation. The data-flow for the whole concept is shown in Fig. 9.

The remaining life line was introduced to describe the load carrying capacity of the gear at any given moment of its operational life. Therefor this line will be used in the calculation of the remaining service-life. The adaptive load spectrum was implemented to deliver more accurate information about the loads occurring in operation, compared to the load spectrum used for the dimensioning of the gear. The adaptive load spectrum will be used within the remaining-service-life-prediction for an accurate prediction of the loads occurring in the further operation.

The calculation can be done with a classic damage accumulation hypothesis or based on a machine-learning approach similar to the one presented in Sect. 4. The output of this calculation will be the number of load cycles tolerable 
Fig. 9 Data-flow for the remaining-service-life-prediction

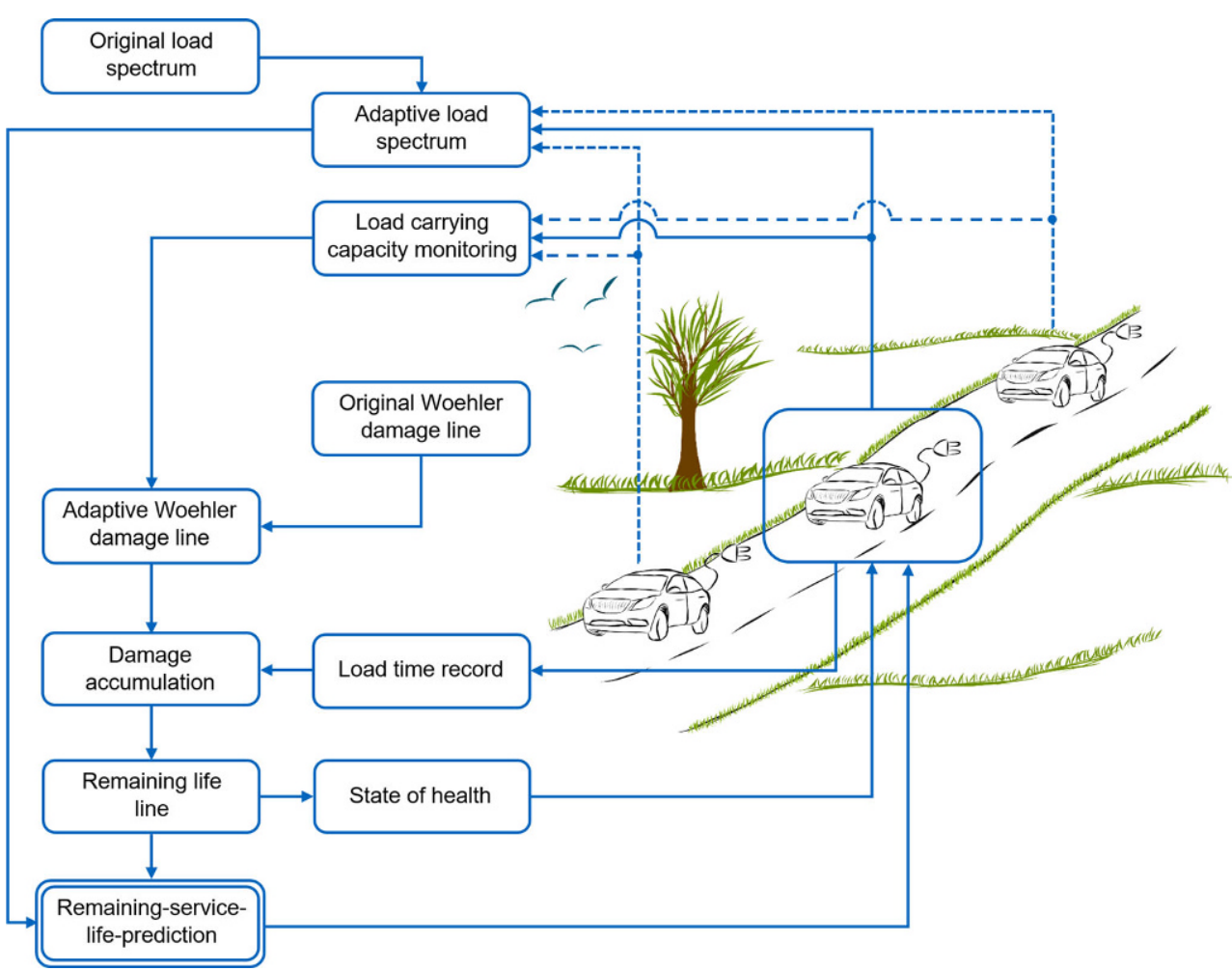

until the gear will fail. This number can be converted into remaining service-time.

Important to consider for this method is the fact, that all of these predictions are connected to a certain probability of failure. This probability usually is one, ten or $50 \%$ in the field of fatigue life analysis depending on the application and the type of failure. For the remaining-service-life-prediction the user has to decide which probability of failure is the right one for his use case. For example, if a failure has severe consequences a lower probability has to be chosen as if the failure has nearly no direct consequences.

The presented approach shares some similarities with the widely known approach of predictive maintenance. Within this approach the need of maintenance and sometimes the remaining service life is predicted. Predictive maintenance usually focuses on the change of sensor-data. For example, if the vibrations exceed a certain threshold or increase significantly within a certain period of time, the algorithms report a need for maintenance.

On the other hand, the method presented within this paper focuses on the whole operational history of a gearbox. This holistic analysis of the occurring loads is able to consider loads which damaged the gears, but may have no detectable influence on their operational behavior yet.

Of courses a combination of the both methods is conceivable and may result in the most accurate prediction of the state of health and the remaining service life.

\section{Conclusion and outlook}

This paper roughly presents a method for a remaining-service-life-prediction for the gears of a vehicle-transmission, but the method can similarly be applied to different machine elements and other machines, like a wind turbine for example. The concept utilizes the relatively new potential and opportunities created by machine-learning and big data analysis. Also does the method not only focus on one single machine, but analysis a whole fleet together and uses knowledge only accessible through this holistic approach.

In the coming steps of the author's research the single elements of the calculation have to be specified and implemented in detail. Especially the use of machine learning requires the construction of a database with a lot of operational data of gears. For this, already existing research data can be used as well as experimental investigations can be conducted to create datasets.

Funding Open Access funding enabled and organized by Projekt DEAL.

Open Access This article is licensed under a Creative Commons Attribution 4.0 International License, which permits use, sharing, adaptation, distribution and reproduction in any medium or format, as long as you give appropriate credit to the original author(s) and the source, provide a link to the Creative Commons licence, and indicate if changes were made. The images or other third party material in this article are included in the article's Creative Commons licence, unless indicated otherwise in a credit line to the material. If material is not included 
in the article's Creative Commons licence and your intended use is not permitted by statutory regulation or exceeds the permitted use, you will need to obtain permission directly from the copyright holder. To view a copy of this licence, visit http://creativecommons.org/licenses/by/4. $0 /$.

\section{References}

1. Barszcz T (2019) Vibration-based condition monitoring of wind turbines vol 14. Springer, Cham https://doi.org/10.1007/978-3030-05971-2

2. Edel K-O (2015) Einführung in die bruchmechanische Schadensbeurteilung. Springer, Berlin Heidelberg https://doi.org/10.1007/ 978-3-662-44264-7

3. Foulard S (2015) Online and real-time load monitoring for remaining service life prediction of automotive transmissions. Damage level estimation of transmission components based on a torque acquisition. TU Darmstadt Dissertation

4. Foulard S, Rinderknecht S, Ichchou M, Perret-Liaudet J (2013) Real-time and online lifetime monitoring of automotive transmissions. Determining of the remaining lifetime of transmission components with the aid of torque measure. In: International Conference on Gears. VDI-Berichte, vol 2199

5. Foulard S, Rinderknecht S, Perret-Liaudet J, Ichchou M (2014) Online and real-time damage calculation in automotive transmissions application to remaining service life estimation. In: International Gear Conference 2014. Conference proceedings, vol II, pp 933-949

6. Foulard S, Rinderknecht S, Fietzek R (2016) Leichtbau von Fahrzeuggetrieben durch Online- und Echtzeit-Lebensdauerüberwachung. ATZ 118(3):74-79

7. Fromberger M, Weinberger U, Kohn B, Utakapan T, Otto M, Stahl K (2016) Condition monitoring by position encoders. In: 45th International Congress and Exposition on Noise Control Engineering INTER-NOISE 2016, Hamburg, Germany (Conference Paper)

8. Fromberger M, Weinberger U, Kohn B, Utakapan T, Otto M, Stahl K (2017) Evaluating signal processing methods for use in gearbox condition monitoring. In: 24th International Congress on Sound and Vibration ICSV 2017, London, United Kingdom (Conference Paper)

9. Fromberger M, Sendlbeck S, Rothemund M, Götz J, Otto M, Stahl K (2019) Comparing data sources for condition monitoring suitability. Forsch Ingenieurwes 83(3):521-527. https://doi.org/10. 1007/s10010-019-00331-y

10. Haibach E (2006) Betriebsfestigkeit. Verfahren und Daten zur Bauteilberechnung. VDI-Buch, Springer Berlin

11. Hein M (2018) Zur ganzheitlichen betriebsfesten Auslegung und Prüfung von Getriebezahnrädern. Dissertation. TU München, München

12. Hein M, Tobie T, Stahl K (2017) Calculation of tooth flank fracture load capacity - practical applicability and main influence parameters. In: American Gear Manufacturers Association Fall Technical Meeting 2017

13. Hein M, Tobie T, Stahl K (2017) Test method for time-scaled fatigue tests of gear transmission systems. Forsch Ingenieurwes 81(2/3):291-297. https://doi.org/10.1007/s10010-017-0226-0

14. Hein M, Geitner M, Tobie T, Stahl K (2018) Reliability of gears-determination of statistically validated material strength numbers. In: American Gear Manufacturers Association Fall Technical Meeting 2018 https://doi.org/10.1007/s10010-017-0226-0 (18FTM26)

15. Miner MA (1945) Cumulative damage in fatigue. J Appl Mech 12(3):159-164

16. Niemann G, Winter H (2003) Getriebe allgemein, Zahnradgetriebe - Grundlagen, Stirnradgetriebe. Maschinenelemente, vol 2. Springer, Berlin

17. Rebala G, Ravi A, Churiwala S (2019) An introduction to machine learning. Springer, Cham

18. Sander M (2018) Sicherheit und Betriebsfestigkeit von Maschinen und Anlagen. Springer, Berlin Heidelberg https://doi.org/10.1007/ 978-3-662-54443-3

19. Schwienbacher S (2004) Schadensrisikominderung. Berücksichtigung von Sonderereignissen bei der Zahnfußtragfähigkeit - Abschlussbericht. FVA-Nr. 374 - Heft 725. Forschungsvereinigung Antriebstechnik e. V., Frankfurt 